\title{
31 Deciphering African informal economies
}

\author{
Kate Meagher
}

\section{Introduction}

The study of African informal economies has undergone yet another about-face in attitudes to informality. Associated with poverty and marginality in the 1970s and 1980s (ILO 1972), viewed as a seedbed of entrepreneurship in the 1990s (MacGaffey1991), and as a source of criminality and corruption from the late 1990s into the first decade of the new millennium (Bayart, Ellis and Hibou 1999), African informal economies have once more been re-branded as a new frontier of growth and innovation (Daniels 2010). In the era of "Africa Rising", informal economies are widely touted as a fount of entrepreneurial dynamism, and as a source of workers and new consumer markets capable of driving ongoing economic growth. What is noteworthy in this panoply of representations of African informality is not just how often the characterisation and attendant policy advice shift, but the tendency to shift from one blanket representation of African informal economies to another, without ever focusing on the possibility of differences among informal economies within the region, except for the conventional division between SubSaharan and North Africa. Inadequate attention is given to important differences among informal economies in Sub-Saharan Africa (Meagher 2014).

\section{Size matters}

The tendency towards homogeneous representations of informality in SubSaharan Africa seems to have been reinforced by the rise of statistical information on informality, even though it is increasingly available at the country level. Sub-Saharan Africa remains the most informalised region in the world, with informality measured at 77 per cent of the non-agricultural workforce and 89 per cent of the total workforce (ILO 2018a). Because African informal economies are generally quite large, there has been relatively little attention to the significant variations in the size of informal economies within the region. While many West African countries have exceptionally large informal economies, in the range of 68-91 per cent of non-agricultural workers, Southern African countries tend to have much smaller informal economies, ranging from 34-55 per cent of the non-agricultural workforce. 


\section{Kate Meagher}

Thandika Mkandawire (2010) has drawn attention to these differences in the size of African informal economies, and to the role of the state in this variation. While some scholars have examined why South Africa has a relatively small informal economy, Mkandawire explains historically why not only South Africa, but a range of Southern African countries and some East African countries such as Kenya, have noticeably smaller informal economies than are found in other parts of Africa. Using Samir Amin's (1972) famous typology of cash crop, labour reserve, and concession economies, Mkandawire traces this to the differential capacities and economic objectives of colonial states. This reinforces the recognition that informal economies are not something that emerges purely outside the state, but that the state plays a role in the different size and character of informal economies.

\section{Making African informal economies legible}

While some attention is now being paid to variations in size, less attention has been paid to differences in local informal institutions that create additional variations between African informal economies. To be sure, there has been a growing interest in the internal regulatory character of African informal economies since the early 1990s. As Julia Elyachar (2005: 73) explains, where vast areas of urban enterprise and national resource flows take place completely outside the control of the state, "informality has become too central ... to be relegated to the sphere of negative phenomena - "the "not formal", ". This recognition invites a closer look at the informal institutional systems that shape how informal economies operate. Particularly in many African countries, where the informal economy is such a significant force, understanding its implications for economic change requires a focus on the actual institutional processes at play, rather than simply assuming how informal economies work on the basis of ideological assumptions and pattern variables. As Keith Hart (2006: 33) observed, "We need to know ... what social forms have emerged to organise the informal economy" and to "examine the institutional particulars sustaining whatever takes place beyond the law".

Growing interest in the regulatory capacities of informal institutions within African informal economies has cast new light on informality as something with potentially constructive modes of organisation. The "new institutionalist turn" has motivated economists and political scientists to take a closer look at the informal regulatory systems, leading to the recognition that the informal economy is not "unorganised" or criminal by definition, but involves a cornucopia of trading networks, credit systems and institutions of labour control that organise economic activity outside the regulatory ambit of the state (Meagher 2010). Management research grounded in the Bottom of the Pyramid (BoP) approach, and corporate interest in penetrating new markets in emerging economies, have also generated growing interest in understanding the institutional organisation of informal economies. This has been accompanied by a new emphasis on making African informal spaces and economic activities "legible" 
to large-scale capital, not by rationalising and formalising them, but by deciphering their inner workings. BoP specialists Stuart Hart and Ted London (2005) insist on the need for business investors to develop "native capability" in order to engage more effectively with local informal markets and workers. This has been accompanied by a wider "inclusive turn" in international development thinking, in which engagement with informal actors and greater inclusion of informal economies in the growth process are the order of the day.

\section{Informal economic inclusion in whose interest?}

Despite the apparently benign focus on inclusion, efforts to grasp the organisational logic of African informal economies often disguise more opportunistic goals. Many corporate actors and policy-makers regard informal economies as a pool of workers, consumers and institutions that can be tapped for new sources of corporate profit. Making informal economies legible to capital is not just about learning to understand and engage with the needs of informal actors, but about using informal workers and institutions to reduce the cost of operating in African slums and remote rural areas.

Inclusive engagement with African informal economies tends to involve forms of interaction that are highly selective. Efforts to make informal economies legible allow useful informal workers and informal institutions to be identified and "included", while less useful informal actors and institutions are further marginalised, and even criminalised (Meagher 2015). In the process, informal economic inclusion is turned into an exercise in restructuring and governing African informal economies in line with the needs of global markets. As Catherine Dolan and Kate Roll (2013) explain, building inclusive markets involves "working" informal economic spaces - classifying, restructuring and managing informal economic systems to meet the needs of global business. These "techniques of governance" serve to reformat informal economic systems and value chains in ways that privilege the reduction of formal sector costs and increase formal sector control, while preserving the "advantages" of low cost informal employment. Instead of addressing informality as a condition of vulnerability, it is viewed as an array of labour and institutional resources to be harnessed rather than transformed.

As a result, deeper ethnographic attention to the organisation of African informal economies has done little to dispel the essentialist perspectives on African informality. Viewed as assortments of organisational resources, African informal economies are distinguished largely in terms of whether they are useful or useless to global capital. Corporate actors focus on connecting with the microend of informal economies, while bypassing more successful informal traders and producers, who are denigrated as exploiters and middlemen. This selective engagement cuts out the very nodes of accumulation through which informal entrepreneurs improve their livelihoods and move out of poverty. Efforts to circumvent avenues of accumulation within the informal economy have been accompanied by an emphasis on introducing minimalist social protection for 


\section{Kate Meagher}

informal workers and micro-producers. The risk of this approach is that, as James Ferguson (2007) pointed out some years ago, supporting the micro-end of the informal economy with limited social protection does not transform informal livelihoods; it just makes them more sustainable. In the process, African informal economies are only viewed in terms of their ability to reduce transaction costs in the formal economy, rather than as livelihood and business systems in their own right.

\section{Varieties of African informal economies}

What has been missing from the emphasis on the legibility of African informal economies is a clear focus on informal economies as economic systems that may vary from one country to another. Inadequate attention is paid to the possibility that differences in history, colonial states, post-independence governments, and the nature of engagement with the global economy might have shaped African informal economies differently. Have strong informal entrepreneurial systems persisted in some countries while being crushed in others? Is informality more strongly associated with poverty or criminality in some countries than in others? Are the policy needs of informal actors different in different contexts? Do informal actors in some contexts need preferential credit or technical support more than social protection? Does social protection promote or distract from social and economic transformation? It is important to consider how informal economies differ from each other, and to build up policy advocacy on the basis of the needs of particular sorts of informal economies.

Distinguishing among different types of African informal economies requires looking at them from the perspective of economic systems shaped by the nature of their interaction with the state but also by historical and institutional differences and by distinctive forms of engagement with the global economy. More attention is needed to how differences in pre-colonial economic organisation have created complex informal business systems in some parts of Africa which are absent in others. Mkandawire (2010) has shown how different types of colonial states gave free rein to informal business networks in former cash crop economies concentrated in West Africa, while smashing and criminalising them in former labour reserve economies located predominantly in Southern Africa, and fostering violent modes of informal labour organisation and control in former concession economies of Central Africa. More recent differences in the postcolonial state have created a new layer of variation, as some states have focused on developing manufacturing industries, others have focused on liberal importexport regimes, and still others suffered prolonged periods of war. Distinctive patterns of smuggling networks, informal manufacturing clusters, migrant labour and criminal gangs emerged from these varied forms of the interface between contemporary informal economies and the state. Engagement with the global economy has also contributed to variations among African informal economies. Bureaucratically effective states and large pools of informal labour have facilitated engagement with global value chains and BoP initiatives. States with 
weaker bureaucratic capacity and more dynamic informal business systems have posed challenges to the penetration of global value chains "from above", while giving rise to the transnational informal economic networks globalising the informal economy "from below".

While this variation across states suggests a high degree of complexity, it can also lead to the identification of distinctive patterns of informal economic organisation. If informal economies are different from each other, policy responses to the informal economy also need to vary, and deeper questions must be asked about what types of inclusion are appropriate. In some cases, where informal economies have developed strong entrepreneurial systems, as in Senegal or Nigeria, state support for small enterprise development may be what is most needed. Where informal economies consist largely of pools of vulnerable labour and bare survival activities, as in South Africa or Namibia, an emphasis on social protection may be more appropriate, while facilitating links between informal labour and formal sector firms may intensify rather than reduce the exploitative processes of labour informalisation. Where informal economic systems involve a high degree of criminality and coercion, as in many parts of Central Africa, efforts of corporate actors to engage with informal economic systems seem illconceived.

\section{Concluding thoughts}

This think piece reflects on the need to pay more attention to the fact that African informal economies have changed over time and developed in very different ways. While informal economies in some African countries offer constructive possibilities for the development of a locally embedded and dynamic private sector, others foster development trajectories of intensifying poverty, economic exclusion and even criminality. In the current era of expanding informality and corporate links across the formal-informal divide, constructive approaches to economic inclusion require more awareness of the divergent trajectories of Africa's informal economies and more differentiated policy thinking. I offer three suggestions to facilitate a more effective approach to these issues.

The first is to move beyond essentialist perspectives on economic informality, generally, and African informality, in particular. African informal economies do not represent a single regulatory logic of non-state organisation. On the contrary, distinctive historical patterns have led to the prevalence of very different logics of informal organisation. Where former cash crop economies, especially in West Africa, are endowed with efficient commercial institutions and ethno-religiously embedded governance arrangements, few such institutions have survived in the former labour reserve or concession economies in Southern and Central Africa. Distinctive informal regulatory logics rather than simple variations in the size of informal economies, have varied effects on contemporary economic development.

A second suggestion is that a more historical approach to economic informality can help to identify how positive as well as negative informal economic 


\section{Kate Meagher}

trajectories emerge. Grounding contemporary informal economic organisation in a richer pre-colonial and colonial institutional context offers new possibilities for understanding contemporary relations between informal and formal economies. Processes of liberalisation and globalisation have unleashed informal entrepreneurship in many former cash crop economies which continue to expand markets while confounding capitalist discipline. Conversely, former labour reserve economies have given rise to contemporary informal economies with limited capacity for entrepreneurship, and former concession economies tend towards more brutal systems of unfree labour. It is important to note that the state and the international actors are as central as embedded local institutions in shaping these varied development trajectories, given their important role in selectively promoting, suppressing, or hijacking socially embedded economic arrangements (Meagher 2015, 2018).

Finally, a more comparative, historical approach to the analysis of contemporary informality may offer the possibility for more constructive and appropriate policy engagement with African informal economies. This contrasts with contemporary policy approaches to informality in Africa, dominated by the suppression of informal activity by modernising officials, and inclusive initiatives emerging from the business and donor communities. Inclusive arrangements promoted through BoP projects and donor experiments with hybrid governance should be treated with caution. More questions need to be raised about the objectives of inclusion: inclusion of which types of informal economies, in whose interest, and on what terms? It matters whether informal economies of entrepreneurship, vulnerable employment or unfree labour are being embedded in the formal economy, and whether these informal arrangements are being harnessed in the interest of global capital, political expediency, or local economic transformation. 